\title{
Proliferation of human peripheral blood mononuclear cells induced by Candida albicans and its cell wall fractions
}

\author{
CLARA M. AUSIELLO,${ }^{*} \dagger$ G. C. SPAGNOLI, ${ }^{\dagger} \dagger$ MARIA BOCCANERA, $\dagger$ IDA CASALINUOVO, $\dagger$ \\ F. MALAVASI,‡ C. U. CASCIANI,* and A. CASSONET§ \\ * Istituto CNR di Tipizzazione Tissutale e Problemi della Dialisi, L'Aquila, \\ + Laboratorio di Batteriologia e Micologia Medica, Istituto Superiore di Sanità, Rome, and \\ $\ddagger /$ stituto di Genetica Medica, Università di Torino, Italy
}

Summary. Glutaraldehyde-inactivated cells and cell-wall fractions of Candida albicans were studied for their capacity to induce or inhibit the in-vitro proliferation of human peripheral blood mononuclear cells (PBMC), as measured by ${ }^{3} \mathrm{H}$-thymidine incorporation. Both the intact cells (CA) and a phosphorylated gluco-mannanprotein complex of the cell wall (GMP), in $\mu \mathrm{g}$ doses, were strong inducers of PBMC proliferation, with a peak of activity at 6-9 days of culture and varying with the PBMC donor. A significant but much lower proliferation was observed on exposure of PBMC to a low-protein ( $<3 \%$ by weight) mannan component (M) of the cell wall. Both a hot-alkali extracted mannan-protein complex (M-alk), comparable to GMP in crude chemical composition, and an alkali-insoluble cell-wall glucan (GG) were inactive. None of the Candida fractions induced a lymphoproliferation of umbilical cord blood cells and all fractions, except GG, were equally effective in binding human anti-Candida antibodies as shown by a sensitive ELISA-inhibition assay. Moreover, a monoclonal antibody against the class II determinant of the HLA complex inhibited PBMC proliferation irrespective of the Candida antigen used. Taken together, the data shows that in inducing lymphoproliferation, Candida fractions act as specific antigens rather than as non-specific mitogens. Use of intact Candida cells and chemically-defined cell-wall components appears preferable to use of undefined antigenic mixtures as stimulators of PBMC proliferation.

\section{Introduction}

Most healthy individuals possess significant levels of antibodies against the immunodominant mannan chains of the outer cell wall of Candida albicans (Odds, 1979). Lymphocyte proliferation in response to Candida extracts, mixtures of undefined antigenic components, are currently used to monitor T-cell dependent immune responses (Brunham et al., 1983; Cox, 1983).

The ability of Candida preparations to stimulate lymphocyte blastogenesis or specific antibody synthesis or both in vitro has been reported by Piccolella et al. (1980), Gettner and MacKenzie (1981), Durandy et al. (1983), De Repentigny and Reiss (1984) and Wirz et al. (1984). However, either

Received 13 Sep. 1985; accepted 9 Dec. 1985.

$\S$ Correspondence and requests for offprints should be sent to: Dr A. Cassone, Medical Mycology Unit, Laboratory of Bacteriology and Medical Mycology, Istituto Superiore di Sanità, Viale Regina Elena, 299-00161 Rome, Italy. crude antigenic mixtures were used, or no details of the chemical composition and antigenicity of the stimulant fraction were given. Moreover, specific antigenic activation was seldom separated from possible non-specific mitogenic effects. In this study, we report the capacity of purified, chemically-defined mannan-rich components of the cell wall of $C$. albicans to modulate human lymphocyte proliferation in vitro. Because lymphocyte proliferation in vivo during colonisation or infection by Candida reasonably involves intact cells of the micro-organism as well as the released antigens, we have also compared the proliferative responses elicited by whole microbial cells to those obtained with cell-wall components.

\section{Materials and methods}

\section{Organism and growth conditions}

C. albicans, strain BP serotype A, from the collection of the Istituto Superiore di Sanità, Rome, Italy, was used 
throughout. This strain, identified as described by Lodder (1970), was routinely maintained on Sabourauddextrose agar at $28 \mathrm{C}$ and, for experimental use, grown with mild agitation in liquid Winge medium (glucose $0.2 \% \mathrm{w} / \mathrm{v}$, yeast extract (BBL. Cockeysville, MD, USA) $0.3 \%)$ until stationary-phase growth $(48 \mathrm{~h})$ was established. Dense washed-cell suspensions were inactivated with glutaraldehyde (Polysciences, PA, USA) $2 \% \mathrm{v} / \mathrm{v}$ in phosphate buffer $(0.12 \mathrm{M}, \mathrm{ph} 7.2)$ for $1 \mathrm{~h}$ at $37^{\circ} \mathrm{C}$, then washed repeatedly with pyrogen-free distilled water for use as whole cells (CA). Yeast-mycelial conversion was induced by suspending $2 \times 10^{7}$ cells $/ \mathrm{ml}$ in $\mathrm{N}$-acetylglucosamine medium as reported by Mattia and Cassone (1979). Mycelial growth was stopped after incubation for $270 \mathrm{~min}$ at $37 \mathrm{C}$, and hyphal elements $(>95 \%)$ inactivated and treated as above.

\section{Preparation of $C A$-antigenic fractions}

A cell-wall fraction (GMP) was obtained by autoclaving washed yeast cells and precipitating the supernate in cold ethanol, according to Sutherland and Wilkinson (1971). After deproteination by chloroform-butanol (Sutherland and Wilkinson, 1971), the aqueous phase was extensively dialysed against $\mathrm{H}_{2} \mathrm{O}$ and then lyophilised. The yield ranged from 0.2 to $0.5 \%$ of cell dry weight, and the material consisted essentially of a glucomannan-protein complex (see below). For ELISAinhibition experiments, a similar fraction was prepared from Saccharomyces cerevisiae as a control. A mannan fraction (M) was prepared as described by Peat et al. (1961). M-alk, a mannan-rich preparation was obtained by hot-alkali extraction of acid-treated cell walls, as reported by Korn and Northcote (1960). An insoluble glucan fraction in the form of "glucan ghosts" (GG) was prepared by cycles of acid and alkali extraction at $100 \mathrm{C}$ as described by Cassone $e t$ al. (1978). This fraction contained about 3\% chitin (Cassone et al., 198I).

\section{Cell separation}

Blood samples were obtained from healthy adult volunteers in preservative-free heparin (Eparin Vitrum, Como, Italy) $100 \mathrm{IU} / \mathrm{ml}$. Peripheral blood mononuclear cells (PBMC) were isolated by centrifugation on a density gradient (Lymphoprep, Nyegard, Oslo, Norway) according to Böyum (1968) and washed twice in RPMI medium (Gibco, Grand Island, NY, USA). Cells were then resuspended in RPMI medium supplemented with $10 \%$ pooled $\mathrm{AB}$ serum and antibiotics (penicillin $100 \mathrm{IU} /$ $\mathrm{ml}$, streptomycin $0.1 \mathrm{mg} / \mathrm{m}^{\text {; }}$ Gibco) (complete medium). In some experiments, PBMC from umbilical-cord blood, separated as described above, were used as responder cells.

\section{Proliferation assays}

Cultures were set up in flat bottomed 96-microwell trays (Nunc. Denmark). PBMC $\left(2 \times 10^{5}\right)$ were stimula- ted with CA or its fractions, at the concentrations indicated. in single experiments. All tests were performed in triplicate. Trays were incubated at $37 \mathrm{C}^{\circ} \mathrm{CO}_{2} 5 \%$ and the cultures harvested on day 6 , unless otherwise stated. Radiolabelled thymidine (methyl- ${ }^{3} \mathrm{H}$-thymidine, $25 \mathrm{Ci} /$ $\mathrm{mMole}, 1 \mathrm{mCi} / \mathrm{ml}$, Amersham, UK) was added to a final concentration of $0.5 \mu \mathrm{Ci} /$ well $18 \mathrm{~h}$ before harvesting. Cultures were harvested by a Titertek cell harvester (Skatron, Oslo, Norway) and ${ }^{3} \mathrm{H}$-thymidine incorporation measured by the two channel ratio, using the external standard method, with a Beckman (Irvine, CA, USA) LS 9100 liquid scintillator system.

In some experiments "commitment" of PBMC proliferation after stimulation with the various $C$. albicans preparations was evaluated as follows: $10^{6} \mathrm{PBMC}$ in $1 \mathrm{ml}$ of complete medium were incubated for up to $2 \mathrm{~h}$ with an optimal concentration of CA, GMP and M, then extensively washed to remove free antigen and further processed as for the proliferation assay.

\section{Mitogen-induced blastogenesis}

Non-specific mitogen-induced blastogenesis was determined by culturing $2 \times 10^{5}$ PBMC in $0.2 \mathrm{ml}$ of complete RPMI medium in flat bottomed 96-microwell trays in the presence of a 1 in 100 dilution of commercial phytohaemagglutinin PHA (HA 15; Wellcome, UK). Pulsing of cultures with ${ }^{3} \mathrm{H}$-thymidine and isotope-incorporation measurement were performed as described above and the incorporation was stopped on day 3 of PHA stimulation.

\section{Inhibition of $C A$-induced proliferative response}

In a series of experiments, $2 \times 10^{5}$ PBMC were incubated at $37^{\circ} \mathrm{C}$ for $1 \mathrm{~h}$ with scalar concentrations of soluble mannan fractions from 0.5 to $100 \mu \mathrm{g} / \mathrm{ml}$. An optimal PBMC-proliferation-inducing amount of CA was then added and the proliferative response evaluated on day 6 as described. In other experiments, a monoclonal antibody (AA 384) against MHC Class-II antigen, prepared and characterised as described by Malavasi et al. (1984), was added at the time of culture seeding to a final concentration of $10 \mu \mathrm{g} / \mathrm{ml}$.

\section{Analytical determinations}

Protein concentrations were determined by the method of Lowry et al. (1951) and carbohydrate concentrations with anthrone reagent as described by Herbert $e t$ al. (1971). For a combined determination of mannan and glucan, the fraction was divided into two parts: one for total carbohydrate and the other for the determination of mannan as the insoluble copper complex after addition of $\mathrm{KOH}(1.0 \mathrm{M}$ final concentration) and Fehling solutions (Peat et al., 1961). The glucan estimate was obtained by subtracting the mannan concentration from that for total carbohydrate. In the estimation of mannan, allowance was made for the lower absorbance (55\%) that this polysaccharide gives relative to the glucose stan- 
dard. Phosphorus present in mannan preparations was determined in perchloric acid-treated samples by the phosphomolybdate complex formation as reported by Herbert et al. (1971).

\section{NMR measurements}

${ }^{31} \mathrm{P}$ NMR spectra of Candida antigens were taken at $4^{\circ} \mathrm{C}$ by means of a Varian FTXL 100-15" spectrometer working at $40.5 \mathrm{MHz}$, interfaced to a 620 -L computer under conditions of broad-band proton decoupling. The field:frequency ratio of the spectrometer was stabilised by locking on $\mathrm{D}_{2} \mathrm{O}$ resonance. Each spectrum represented the Fourier transform of accumulated free induction decay, obtained with a sequence of $60^{\circ}$ pulses and acquisition time of $1.50 \mathrm{~s}$. The chemical shift was measured in $\mathrm{ppm}$ relative to the $85 \% \mathrm{w} / \mathrm{v}$ phosphoric acid as external standard.

\section{Enzyme-linked immunosorbent assay (ELISA)}

Assays were performed in polystyrene microtitration plates (Dynatech, Microelisa, CA, USA). Of the antigenic fractions at concentrations of $5 \mu \mathrm{g} / \mathrm{ml}, 200 \mu 1$ were added to wells, held overnight at $4{ }^{\circ} \mathrm{C}$, and subsequently rinsed with phosphate-buffered saline (PBS; $0.1 \mathrm{M}, p \mathrm{H}$ $7.4)$ containing Tween $20 \times 30.05 \% \mathrm{v} / \mathrm{v}$. Then $200 \mu \mathrm{l}$ of hyperimmune human serum (ELISA titre $>128000$ ) from a candidosis-convalescent donor was added, at the desired dilution, and plates incubated for $1 \mathrm{~h}$ at room temperature. After careful washings with Tween 20 PBS buffer, $200 \mu \mathrm{l}$ of a 1 in 1000 dilution of goat antihuman IgG-alkaline phosphatase conjugate (Sigma Chemical Co., St Louis, MO, USA) was added for $1 \mathrm{~h}$ and enzyme activity was detected by adding nitrophenylphosphate reagent (Sigma). The reaction was terminated by adding $50 \mu$ lo a $3 \mathrm{M} \mathrm{NaOH}$ solution after $20 \mathrm{~min}$. In some experiments, ELISA-inhibition tests were performed with cell-wall preparations of $C$. albicans. Compounds tested as inhibitors were added, at suitable dilutions, to hyperimmune human serum and left overnight at room temperature, then the mixtures were added to antigen-coated wells and the immunosorbent assay performed as described above. The ELISA tests were read with the automated microreader Titertek Multiscan (Skatron, Oslo, Norway), set at $405 \mathrm{~nm}$ and blanked against air. Tests were performed in triplicate and the OD of the well without a Candida coating antigen was taken as the background reading. A positive test was one with at least twice the absorbance of the background reading and the inhibition was taken as significant only when the mean value of triplicate samples with inhibitor was at least $50 \%$ less than the mean value of triplicate samples without inhibitor, at any given serum dilution.

\section{Statistical analysis}

Statistical analysis was performed by Student's $t$ test (un-paired data).
Table I. Proliferative response* to $\mathrm{CA}$ by human $\mathrm{PBMC}$, as measured by ${ }^{3} \mathrm{H}$-thymidine incorporation

\begin{tabular}{|c|c|c|c|c|}
\hline \multirow[b]{2}{*}{ Material } & \multirow{2}{*}{$\begin{array}{c}\text { Dose } \\
(\mu \mathrm{g} / \mathrm{ml})\end{array}$} & \multicolumn{3}{|c|}{$\begin{array}{c}{ }^{3} \mathrm{H} \text {-thymidine incorporated } \dagger \\
\left(\mathrm{dpm} \times 10^{-3} \pm \mathrm{SD}\right) \text { by PMBC from }\end{array}$} \\
\hline & & donor 1 & donor 2 & donor 3 \\
\hline nonef & $\ldots$ & $4.6 \pm 1 \cdot 7$ & $3 \cdot 9 \pm 0 \cdot 2$ & $2 \cdot 2 \pm 1 \cdot 2$ \\
\hline none $\$$ & $\ldots$ & $2 \cdot 1 \pm 0 \cdot 1$ & $1.6 \pm 0.3$ & $0.9 \pm 0.1$ \\
\hline CA & 50 & $52 \cdot 1 \pm 17.6$ & $158 \cdot 6 \pm 19 \cdot 2$ & $73 \cdot 8 \pm 21.8$ \\
\hline CA & 5 & $41 \cdot 1 \pm 7 \cdot 7$ & $22 \cdot 3 \pm 2 \cdot 0$ & $79 \cdot 9 \pm 21 \cdot 3$ \\
\hline CA & 0.5 & $15 \cdot 6 \pm 7 \cdot 3$ & $17 \cdot 1 \pm 6 \cdot 2$ & $7 \cdot 2 \pm 2 \cdot 1$ \\
\hline PHA & $\begin{array}{l}1 \text { in } 100 \\
\text { dilution }\end{array}$ & $232 \cdot 9 \pm 41 \cdot 4$ & $261 \cdot 1 \pm 14.9$ & $126 \cdot 5 \pm 13 \cdot 2$ \\
\hline
\end{tabular}

* Proliferation was assessed in triplicate samples each containing $2 \times 10^{5} \mathrm{PBMC}$ in a final volume of $0.2 \mathrm{ml} /$ well.

$\uparrow^{3} \mathrm{H}$-thymidine was added $18 \mathrm{~h}$ before harvesting the culture. Thymidine incorporation values were measured on day 3 after addition of PHA or day 6 after addition of CA.

$\$ \$$ Controls for PHA and CA stimulated cultures, respectively.

|) Used at 1 in 100 dilution of a commercial preparation.

\section{Results}

Capacity of inactivated cells of C. albicans to stimulate human lymphocyte blastogenesis in vitro

The proliferative response of PBMC to CA was assessed in 25 healthy donors. Table I shows ${ }^{3} \mathrm{H}$ thymidine incorporation values in a representative experiment with three donors. CA strongly induced lymphoproliferation, optimal responses being recorded in the concentration range $5-50 \mu \mathrm{g} / \mathrm{ml}$; the response also depended on the specific donor. The PBMC of all donors responded to the nonspecific activator PHA. CA, at concentrations up to $50 \mu \mathrm{g} / \mathrm{ml}$, did not significantly affect the response to PHA ( $p>0.05$; data not shown).

The kinetics of the proliferative response induced by $\mathrm{CA}$ was also studied. Fig. 1 shows that, with PBMC from a single donor, the optimal proliferative response was detected on day 9 of PBMC culture; the response then declined. With PBMC from a panel of donors, the optimum time of proliferation was in the range 6-9 days. In no case was a proliferative PBMC response observed on day 3, when the PHA-induced proliferation was usually maximal.

Because $C$. albicans may grow, either in vitro or in vivo, in two different forms - yeast (Y) or mycelial (M) - and these may express form-specific antigens (Smail and Jones, 1984), we also compared the abilities of $\mathrm{Y}$ and $\mathrm{M}$ forms to stimulate blastogenesis. PBMC from all the donors responded with a similar efficiency and kinetics to the two growth forms (data not shown). 


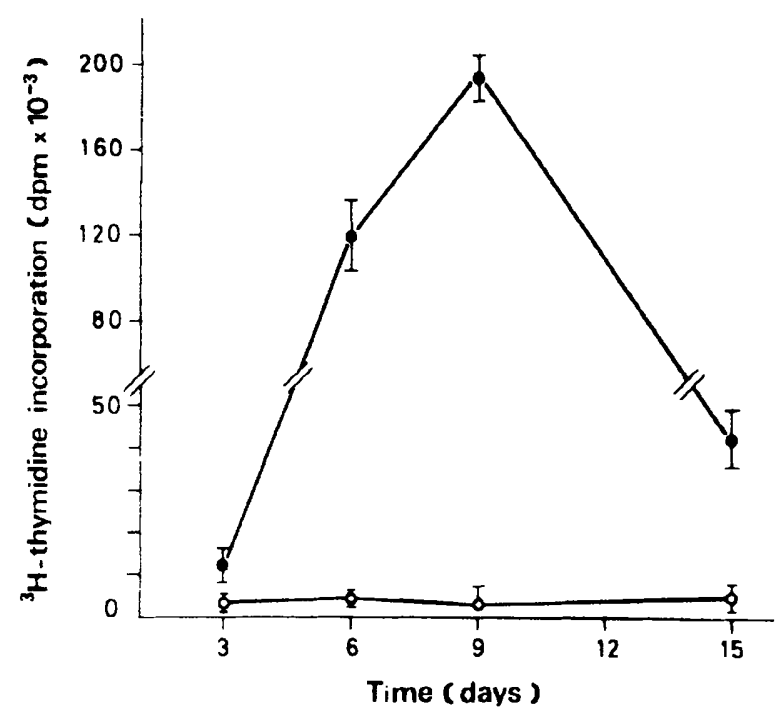

Fig. 1. Kinetics of $\mathrm{C} A$-induced proliferation in a representative donor. PBMC $\left(2 \times 10^{5}\right)$ were cultured (triplicate samples) in the absence ( - . $)$ or in the presence (-) of CA $50 \mu \mathrm{g} / \mathrm{ml}$. ${ }^{3} \mathrm{H}$-thymidine incorporation was measured on the indicated days. The vertical bar indicates $\pm \mathrm{SD}$.

Chemical and antigenic properties of cell-wall fractions

Comparative experiments were undertaken with $\mathrm{CA}$ and three mannan-rich fractions with the biochemical properties shown in table II and fig. 2 . GMP is a cell wall fraction characterised by: (i) relatively high protein content $(8 \%$ by weight); (ii) mannan as predominant polysaccharide component; and (iii) a high phosphorus: mannose ratio, as demonstrated both by chemical determination (table III) and by spectrometric ${ }^{31} \mathrm{P}$ NMR analysis (fig. 2) which showed that phosphorus was present as phosphodiester (a single peak with a chemical shift at around $1.0 \mathrm{ppm}$ with respect to an inorganic phosphate standard).

Table II. Chemical composition of whole cells and cellwall fractions of $C^{\prime}$. alhicans

\begin{tabular}{|c|c|c|c|c|}
\hline Material & Protein & $\begin{array}{l}\text { Polysatc- } \\
\text { charide }\end{array}$ & Mannan & $\begin{array}{l}\text { Phos- } \\
\text { phorus }\end{array}$ \\
\hline$\left(A^{*}\right.$ & $27 \cdot 3$ & $23 \cdot 0$ & $8 \cdot 1(35.2)_{+}^{+}$ & N.D. \\
\hline$C i(i \div$ & 0.1 & 9.4 .3 & $1.2(1.27)_{+}^{+}$ & N.D. \\
\hline (iMP- & $8 \cdot(1)$ & 850 & $83.7(98.4)_{+}^{+}$ & $6 \cdot 4$ \\
\hline $\mathrm{M}-\mathrm{ill}+\mathrm{t}$ & $12 \cdot 0$ & $75 \cdot 0$ & $66.6(88.8)_{+}^{+}$ & N.D. \\
\hline \multirow[t]{2}{*}{$M:$} & 35 & $95 \cdot 8$ & $88 \cdot 0(91 \cdot 8)_{+}^{+}$ & 6.0 \\
\hline & & & .... & - \\
\hline
\end{tabular}

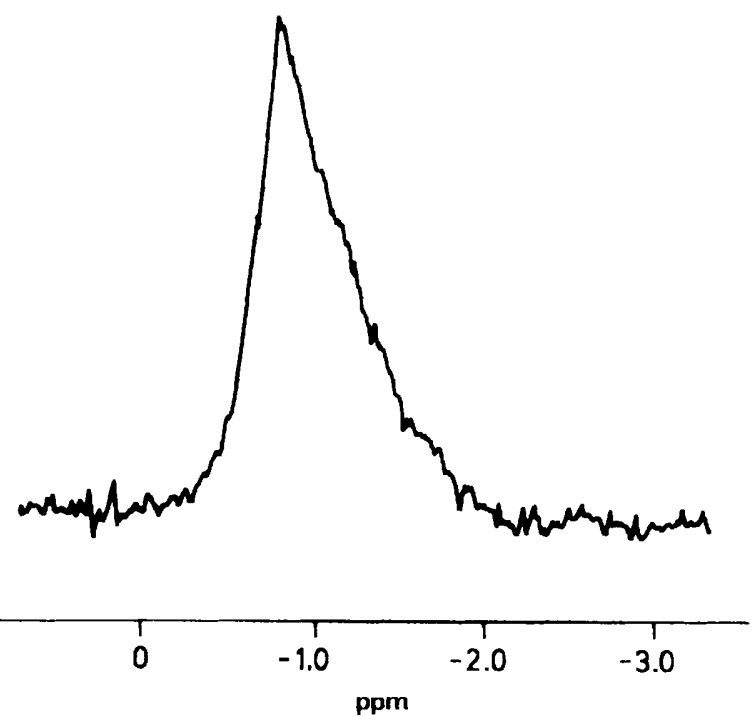

Fig. 2. ${ }^{3} P$ NMR spectrum of GMP fraction of $C$. albicans. The spectrum was taken at $40.5 \mathrm{MHz}, 4 \mathrm{C}$ and represented 15000 free induction-decays.

The cell-wall component $\mathbf{M}$ was mannan with protein c. $3 \%$ by weight and phosphorus $6 \%$ in phosphodiester bonds (data not shown). M-alk consisted of $c .75 \%$ polysaccharide with a predominant mannan composition and about $12 \%$ protein. Finally, insoluble glucan, as rigid cell wall skeletons ("glucan ghosts") and essentially devoid of mannan (1.2\% by weight) was also examined (table II).

GMP and $M$, but not $M$-alk, acted as solidphase antigens in the detection of human antiCandida antibodies in the ELISA indirect technique. M-alk inhibited the immunosorbent assay with GMP or $\mathrm{M}$ as coating antigens, and its inhibitory potency was comparable to that of GMP and $M$, as shown in fig., 3 . The specificity of this reaction was shown by the absence of inhibition with GMP or M-alk from $S$. cerevisiae.

Lymphocyte blastogenesis induced by cell-wall fractions

Stimulation of human lymphocyte blastogenesis by cell-wall fractions is shown in fig. 4 , which shows data from independent experiments with PBMC from two donors. Soluble GMP was most active, with an optimal response in the dose range $50-100 \mu \mathrm{g} / \mathrm{ml}$. Although to a different extent, all the donors tested were as responsive to GMP as they were to CA. $M$ fraction was active but the proliferation was less and much more variable than with GMP. The activities of the soluble fractions 


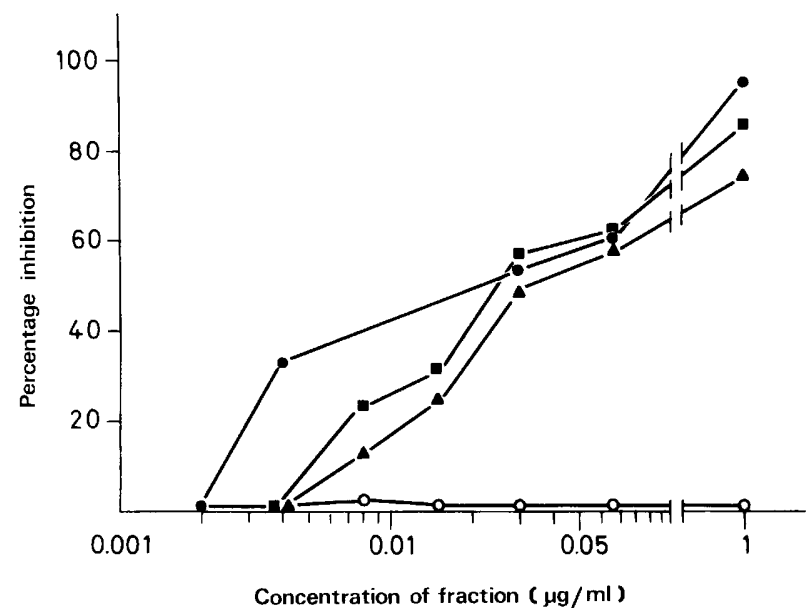

Fig. 3. Inhibition of indirect ELISA (GMP coating antigen, hyper-immune human serum as antibody) by $\mathbf{M}(-\mathbf{\Delta}-)$, M-alk (- - ) , and GMP (- - ) from C. albicans or GMP from $S$. cerevisiae $(\mathrm{O}-\mathrm{O})$.

and $\mathrm{CA}$ in the PBMC of all donors are compared in fig. 5. Induction by GMP and $M$ fractions required contact with PBMC for only $2 \mathrm{~h}$ to "commit" the responder cells to maximal proliferation as observed in experiments where the PBMC were treated for various periods and then the antigens were washed away and the PBMC were reincubated up to 6 days without any stimulant (fig. 6). The $\mathrm{M}$-alk and GG preparations were completely ineffective in stimulating blastogenesis at any concentration up to $100 \mu \mathrm{g} / \mathrm{ml}$ in the PBMC tested (fig. 4).

Because yeast mannan has been reported to suppress lymphocyte blastogenesis (Fischer et al., 1978; Nelson et al., 1984) we studied the capacity of soluble wall fractions of $C$. albicans to inhibit CAinduced lymphoproliferation. PBMC were incubated for $1 \mathrm{~h}$ at $37^{\circ} \mathrm{C}$ with the soluble component, then an optimal concentration of CA was added and the culture tested for ${ }^{3} \mathrm{H}$-thymidine incorporation, in the conditions described. As shown in table III, $\mathrm{M}$ and $\mathrm{M}$-alk significantly inhibited CAinduced lymphoproliferation. PBMC treated with both these fractions remained viable for at least 9 days from the beginning of the treatment with no evidence of toxicity. $\mathbf{M}$ and $\mathbf{M}$-alk did not inhibit PHA-induced proliferation.

Supplementary studies on the proliferative response of human PBMC to CA and cell-wall fractions

The experiments reported did not fully discriminate against a possible non-specific mitogenic effect of the preparations. Therefore, experiments were performed with PBMC from umbilical-cord blood; the proliferative responses of PBMC to $\mathrm{CA}$ and CA-materials were inhibited by monoclonal antibodies directed against HLA-determinants. As shown in table IV, umbilical-cord blood lymphocytes, while optimally responding to PHA, were not stimulated to proliferate by CA or GMP. In other experiments, not shown, the monoclonal antibody A384, directed against a monomorphic determinant, class-II specific HLA DR molecule (Malavasi et al., 1984), inhibited the proliferative response of PBMC to all the $C$. albicans preparations.

\section{Discussion}

In this study, the in-vitro proliferation of PBMC of normal, healthy individuals in response to chemically-characterised cell-wall fractions of $C$. albicans has been compared with that induced by whole $C$. albicans cells (CA). Although CA was the most powerful stimulant of PBMC proliferation, soluble mannan and glucomannan complexes were also active. The insoluble glucan and an alkalidegraded mannan-protein complex were devoid of lymphocyte stimulating activity. Mannan components, in addition to PBMC stimulatory activity, were shown to inhibit the lymphoproliferation induced by intact $\mathrm{CA}$.

The soluble mannan fractions GMP and $M$, which induced significant lymphoproliferation, contained constituents which bind anti-C. albicans antibodies, as shown by the ELISA results with high-titre human serum. Moreover, both fractions specifically inhibited the haemagglutination reaction between the same serum and $C$. albicansmannan-coated red blood cells (data not shown). This antigenicity, together with the chemical composition, suggests that both GMP and M owe their antigenicity to mannan structures and that their capacity to induce lymphoproliferation is due to antigenic rather than non-specific activation. Evidence for this conclusion came from experiments performed with PBMC from umbilical-cord blood, which showed an optimum response to PHA but no response to $C$. albicans antigens. Experiments showing the kinetics of ${ }^{3} \mathrm{H}$-thymidine incorporation (maximum peak at days 6-9 of the culture), the existence of a "commiting" step in the proliferation, and the capacity of a monoclonal antibody directed against a monomorphic determinant of MHC class-II antigens (Malavasi et al., 1984) to inhibit strongly both CA- and mannan-induced proliferation, present further evidence in support of the above conclusion. 


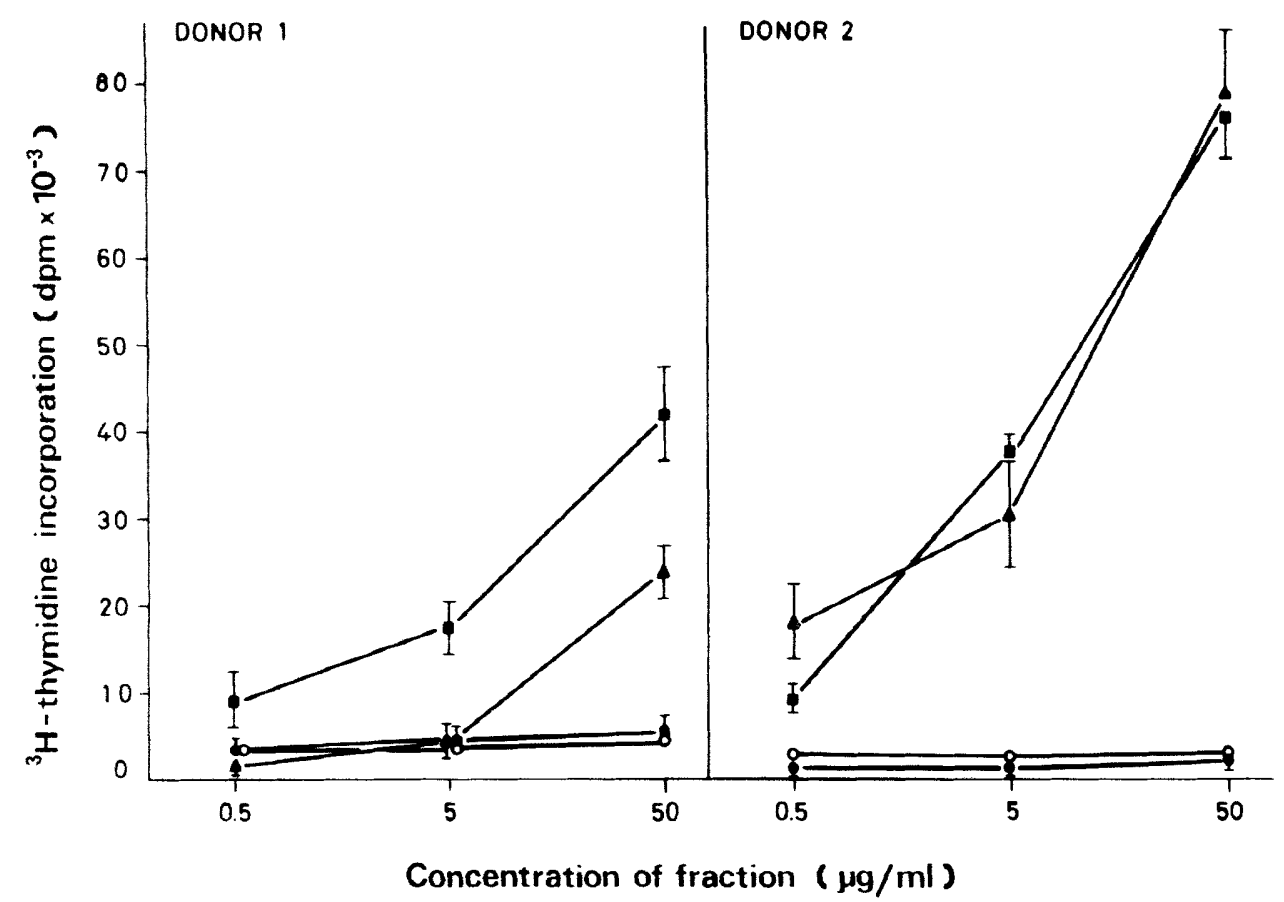

Fig. 4. PMBC proliferation in response to cell-wall fractions of $C$. albicans. The data represent dose-response curves, measured as ${ }^{3} \mathrm{H}$-thymidine incorporation on day $6-\mathrm{GMP},-\mathbf{-}-\mathbf{M},-\mathbf{\Delta -} ; \mathrm{M}$-alk, $-\mathbf{-}-; \mathrm{GG},-\mathrm{O}-$. Control values of unstimulated cultures were $\left(10^{3}\right) 3 \cdot 9 \pm 0 \cdot 2$ (donor 1$)$ and $2 \cdot 1+3$ (donor 2 ).

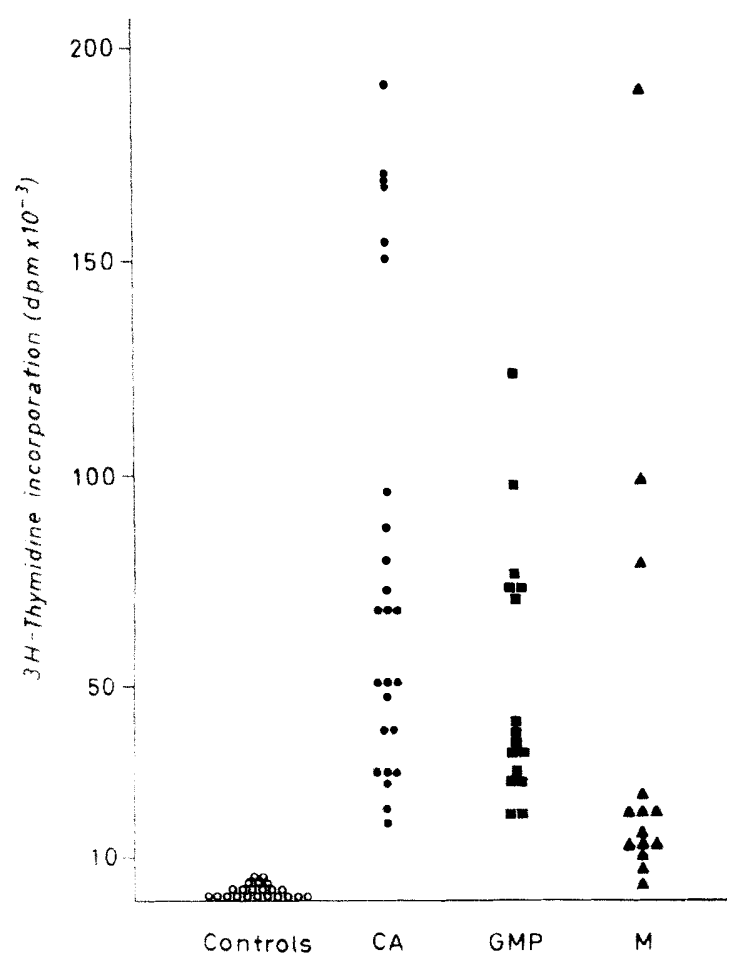

Fig. 5. PBMC proliferative responses of healthy human donors to $\wedge 5 \mu \mathrm{g} \mathrm{ml}(O)$. GMP $50 \mu \mathrm{g} / \mathrm{ml}$ ( $)$ ). M $50 \mu \mathrm{g} / \mathrm{ml}$ ( $\mathbf{A})$, unstimulated cultures ( ). The proliferative response was assessed by ${ }^{3} \mathrm{H}$-thymidine incorporation on day 6 .
The GMP fraction described here was a very active, soluble antigenic stimulator which might correspond to the antigenic activator (MPPS) reported by Piccolella et al. (1980) although these authors reported no details of their preparation. Chemical analysis of GMP showed it to be a glucomannan protein complex with phosphorus present in the form of phosphodiester bonds, as shown by ${ }^{31} \mathrm{P}$ NMR spectra of the compound, and as expected from the nature of the immunodominant mannan chain (Suzuki and Fukazawa, 1982).

Although less effective, significant lymphoproliferation was obtained with $\mathrm{M}$, a low-protein mannan preparation. This mannan was fractionated into several components by DEAE-Sephadex chromatography and it also had a prominent phosphodiester peak in ${ }^{31} \mathrm{P}$ NMR spectrum (data not shown). A failure of low-protein mannan to stimulate lymphocyte blastogenesis or specific antibody synthesis in vitro has been reported by Gettner and MacKenzie (1981), Durandy et al. (1983) and Nelson et al. (1984). The reasons for this are not known but mannan preparations of similar crude chemical composition derived from different strains of $C$. albicans may vary in immunogenicity. Moreover mannan may be degraded when an alkali extraction step is included during preparation, as shown here with M-alk. However, alkali-degraded 


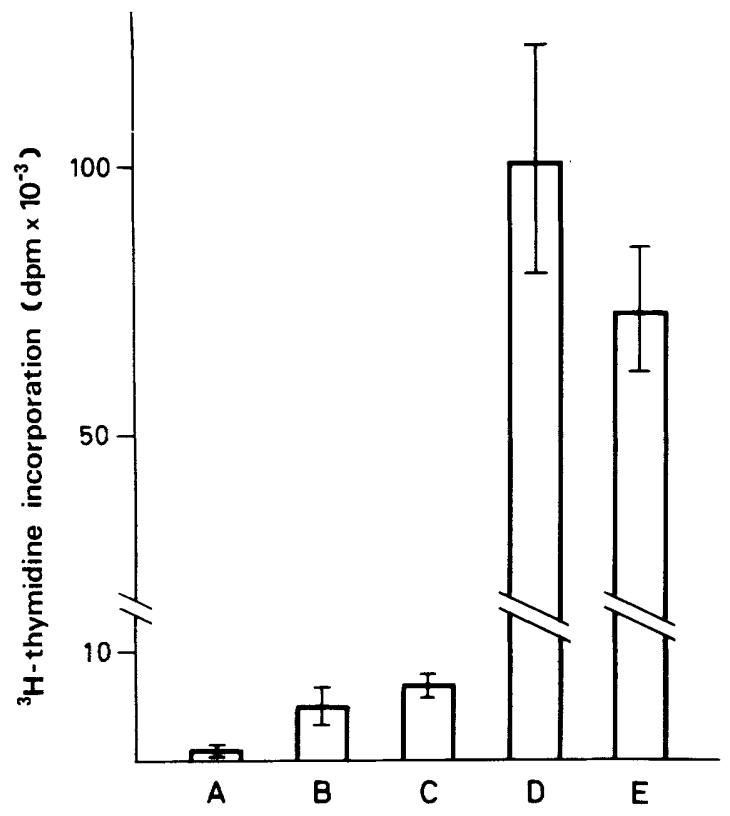

Fig. 6. Time necessary for the induction of $P B M C$ proliferative response to $C$. albicans cell-wall fractions $(50 \mu \mathrm{g} / \mathrm{ml})$. The response was assayed after the following treatments: $A$, medium only for $2 \mathrm{~h}$, wash, culture for 6 days (control); B, M fraction $2 \mathrm{~h}$, wash, culture for 6 days in medium; $\mathrm{C}, \mathrm{M}$ fraction $2 \mathrm{~h}$, wash, culture for 6 days in $M$ fraction; D, GMP fraction $2 \mathrm{~h}$, wash, medium culture for 6 days in medium; E, GMP fraction $2 \mathrm{~h}$, wash, culture for 6 days in GMP fraction. Proliferation was measured on day 6 by the standard ${ }^{3} \mathrm{H}$-thymidine test. Bars represent $\pm \mathrm{SD}$.

Table III. Inhibitory effects of $\mathrm{M}$ and $\mathrm{M}$-alk on CAinduced PBMC proliferation*

\begin{tabular}{|c|c|c|c|c|}
\hline \multirow[b]{2}{*}{ Material } & \multicolumn{4}{|c|}{$\begin{array}{l}{ }^{3} \mathrm{H} \text {-thymidine-incorporated } \\
\qquad\left(\mathrm{dpm} \times 10^{-3} \pm \mathrm{SD}\right)\end{array}$} \\
\hline & $(\mu \mathrm{g} / \mathrm{ml})$ & without CA & with CA & \\
\hline none & - & $0.7 \pm 0.04$ & $51 \cdot 3 \pm 0 \cdot 9$ & \\
\hline M & 100 & $7 \cdot 8 \pm 0 \cdot 6$ & $23 \cdot 4 \pm 5 \cdot 7 \dagger$ & (54) \\
\hline M & 50 & $11 \cdot 2 \pm 0 \cdot 7$ & $32 \cdot 1 \pm 6 \cdot 8$ & (37) \\
\hline $\mathrm{M}$ & 25 & $11 \cdot 7 \pm 0 \cdot 6$ & $33 \cdot 1 \pm 4 \cdot 4$ & (35) \\
\hline M-alk & 100 & $0 \cdot 8 \pm 0.06$ & $24 \cdot 0 \pm 1 \cdot 9 \ddagger$ & (53) \\
\hline M-alk & 50 & $0 \cdot 9 \pm 0 \cdot 1$ & $28 \cdot 3 \pm 2 \cdot 5$ & (45) \\
\hline M-alk & 25 & $1 \cdot 2 \pm 0 \cdot 05$ & $29 \cdot 7 \pm 3 \cdot 6$ & (42) \\
\hline
\end{tabular}

* Proliferation was assessed in triplicate samples each containing $2 \times 10^{5} \mathrm{PBMC}$. Cells were incubated for $1 \mathrm{~h}$ with the indicated fraction and then with CA $5 \mu \mathrm{g} / \mathrm{ml}$ until day 6 , when ${ }^{3} \mathrm{H}$ thymidine incorporation was measured. Values in parentheses represent the percentage of inhibition with respect to $\mathrm{CA}$ induced proliferation.

$\dagger \mathrm{p}<0.05$.

$\pm \mathrm{p}<0.01$, when compared with the control (CA: first row, "with CA'column).
Table IV. Response to CA and GMP antigens of human umbilical cord blood cells*

\begin{tabular}{|c|c|c|c|}
\hline \multirow[b]{2}{*}{ Material } & \multirow{2}{*}{$\begin{array}{c}\text { Dose } \\
(\mu \mathrm{g} / \mathrm{ml})\end{array}$} & \multicolumn{2}{|c|}{$\begin{array}{c}{ }^{3} \mathrm{H} \text {-thymidine incorporated } \\
\left(\mathrm{dpm} \times 10^{-3} \pm \mathrm{SD}\right) \text { by cells from }\end{array}$} \\
\hline & & donor 1 & donor 2 \\
\hline none & & $1 \cdot 6 \pm 0 \cdot 22$ & $4.60 \pm 0.8$ \\
\hline PHA & 1 in 100 dilution $\dagger$ & $92 \cdot 6 \pm 6 \cdot 1$ & $16 \cdot 0 \pm 2 \cdot 52$ \\
\hline \multirow[t]{3}{*}{$\mathrm{CA}$} & 50 & $1.62 \pm 0.51$ & - \\
\hline & 5 & $2 \cdot 59 \pm 0.42$ & $3.4 \pm 0.45$ \\
\hline & 0.5 & $1 \cdot 91 \pm 0 \cdot 12$ & - \\
\hline \multirow[t]{3}{*}{ GMP-1† } & 100 & $2 \cdot 82 \pm 0 \cdot 20$ & - \\
\hline & 50 & $2.66 \pm 0.46$ & - \\
\hline & 5 & $1 \cdot 60 \pm 0.71$ & - \\
\hline \multirow[t]{3}{*}{ GMP- $2 \ddagger$} & 50 & $2 \cdot 06 \pm 0 \cdot 34$ & $3.6 \pm 0.05$ \\
\hline & 5 & $2 \cdot 01 \pm 0 \cdot 16$ & $4.8 \pm 1.00$ \\
\hline & 0.5 & $1 \cdot 80 \pm 0 \cdot 17$ & $2 \cdot 7 \pm 0 \cdot 50$ \\
\hline
\end{tabular}

* Proliferation was assessed by measuring ${ }^{3} \mathrm{H}$-thymidine incorporation on day 6 in triplicate samples containing $2 \times 10^{5}$ cord blood cells in a final volume of $0 \cdot 2 \mathrm{ml} / \mathrm{well}$.

$\dagger$ A 1 in 100 dilution of a commercial preparation.

$\$$ Two independent preparations of the same antigen.

mannan was shown to bind anti-Candida antibodies in the ELISA tests described. We cannot exclude the possibility that a small amount of protein or some undefined component in our preparation could have contributed to our $M$ fraction acting as a blastogenic antigen.

We have shown that all mannan preparations inhibited $C$. albicans cell-induced lymphoproliferation. Fisher et al. (1982), working with Candida metabolic antigen as a stimulator and a mannan prer sration similar to our $\mathrm{M}$ fraction as inhibitor, ascribed the inhibition of blastogenesis to a mannan-mediated interference with antigen presentation by adherent cells. This mechanism could even operate more efficiently when the lymphoproliferative stimulus is given by particulate Candida. However, considering the antigenic nature of the lymphoproliferation induced by GMP and $\mathrm{M}$ and the fact that $C$. albicans has mannan polysaccharide chains on its surface (Cassone et al., 1978; Odds, 1979; Suzuki and Fukazawa, 1982), the capacity of mannan fractions to inhibit CAinduced lymphocyte blastogenesis could be due to competition for binding to responsive target cells, as also suggested by Nelson et al. (1984), for the inhibition by Saccharomyces mannan of Candidaantigen stimulated blastogenesis. Other explanations are possible including generation of suppressor cells (Piccolella et al., 1981). The mechanism of inhibition and its specificity await further studies. Nevertheless, the fact that mannan preparations, even of different composition and structure, may 
inhibit the proliferative response to Candida is a potentially relevant factor in the pathogenesis of candidosis, when consideration is given to the significant amount of mannan antigens secreted by the invading micro-organism in patients affected by systemic candidosis (De Repentigny and Reiss. 1984).

\section{REFERENCES}

Bivum A 1968 Isolation of mononuclear cells and granulocytes from human blood. Isolation of mononuclear cells by one centrifugation and of granulocytes by combining centrifugation and sedimentation at one 9 . Scandinavian Journal of Clinical and Lahoratory Inestigations 21 (Suppl 97):77-89.

Brunham RC. et al. 1983 Depression of the lymphocyte transformation response to microbial antigens and to Phytohemagglutinin during pregnancy. Journal of Clinical Investigation 72:1629 1638 .

Cassone A. Mattia E. Boldrini L 1978 Agglutination of blastospores of Cundida albicans by Concanavalin $A$ and its relationship with the distribution of mannan polymers and the ultrastructure of the cell wall. Joumal of General Microbiology 105:263-273.

Carsonc A at al. 1981 Immunoadjuxant eflects of Candida alhi(ams and its cell wall fractions in a mouse lymphoma model. Cime timmunologl and Immunotherapy 10:181 190.

Cox R A 1983 Cell-mediated immunity. In: Howard D H (ed) Fungi pathogenic for humans and animals. part B. Marcel Dekker. New York, p. 6198

De Repentigny L. Reiss E 1984 Current trends in immunodiagnosis of Candidiasis and Aspergillosis. Reviens of InterIions Diseases 6:301 312 .

Durandy A. Fischer A. Griscelli C 1983 Specific in vitro antimannan-rich antigen of Candida alhicans antibody production by sensitized human blood lymphocytes. Journal of Clinical Investigation 71:1602-16!3.

fincher A. Ballett JJ. Griscelli ( 1978 Specitic inhibition of in vitro Candida-induced lymphocyte proliferation by polysaccharidic antigens present in the serum of patients with chronic mucocutaneous candidiasis. Journal of Clinical $\mathrm{m}$ restigations 62:1005-1013

Fischer A. Pichat 1. Audinot M. Griscelli C 1982 Defective handling of mannan by monocytes in patients with chronic mucocutaneous candidiasis resulting in a specific cellular unresponsiveness. Clinical and Experimental Immunology. 47:653 660.

Gettner SMM, Mackenzie DWR 1981 Responses of human peripheral lymphocytes to soluble and insoluble antigens of Candida alticans. Journal of Medical Microbiology 14:333 340 .

Herbert D. Phipps PJ. Strange R E 1971 Chemical analysis of microbial cells. In: Norris J R. Ribbons D W (eds) Methods in microtiolegy, 5B. Academic Press, London. pp 209 344

Korn E D. Northcote D H 1960 Physical and chemical proper-
This work was supported in part by grants from C.N.R (Italy), Special Project "Oncologia" (Contract No 84.00498.44). The authors wish to thank the Centro Trasfusionale Ospedaliero. U.S.L. RM 3 for kind co-operation in supplying blood samples of human volunteers. Thanks are also due to $\mathrm{Mr}$ S. Valia for expert technical assistance.

ties of polysaccharides and glycoproteins of the yeast-cell wall. Biochemical Journal 75:12-17.

Lodder J 1970 The yeasts; a taxonomic study, 2nd edn. North Holland Publishing Co., Amsterdam, the Netherlands.

Lowry O H, Rosenbrough N J. Farr A L. Randall R J 1951 Protein measurement with the Folin phenol reagent. Journal of Biological Chemistry 193:265 275.

Malavasi $F$ et al. 1984 Generation and characterization of murine monoclonal antibodies against HLA class II molecules. Diagnostic Immunology 2: 53-62.

Mattia E. Cassone A 1979 Inducibility of germ-tube formation in Candida albicans at different phases of yeast growth. Journat of General Microbiology 113:439-442.

Nelson R D. Herron M J, McCormack R T. Gehrz R C 1984 Two mechanisms of inhibition of human lymphocyte proliferation by soluble yeast mannan polysaccharide. Infection and Immunity 43:1041- 1046.

Odds F C 1979 Candida and candidosis. Leicester University Press, Leicester, pp $205-307$.

Peat S, Whelan W J, Edwards T E 1961 Polysaccharides of baker's yeast. Part IV Mannan. Journal of Chemical Society $29-34$.

Piccolella E. Lombardi G, Morelli R 1980 Human lymphocyteactivating propertics of a purified polysaccharide from Candida albicans: $\mathrm{B}$ and $\mathrm{T}$ cell cooperation in the mitogenic responses. Journal of Immunology 125:2082--2088.

Piccolella E, Lombardi G, Morelli R 1981 Generation of suppressor cells in the response of human lymphocytes to a polysaccharide from Candida albicans. Journal of Immunology 126:2151 2155 .

Smail E H. Jones J M 1984 Demonstration and solubilization of antigens expressed primarily on the surfaces of Candida albicans germ tubes. Infection and Immunity 45:74 81 .

Sutherland I W, Wilkinson J F 1971 Chemical extraction methods of microbial cells. In: Norris J R, Ribbons D W, eds. Methods in microbiology, 5B. Academic Press, London pp $345-383$.

Suzuki M. Fukazawa T 1982 Immunochemical characterization of Candida alhicans cell wall antigens: specific determinant of Candida albicans serotype A mannan. Microbiology and Immunology 26:387-402.

Wirz M, Lombardi G, Pugliese O, Morelli R, Piccolella E 1984 A purified polysaccharide isolated from Candida albicans induces antibody response in vitro by human peripheral blood lymphocytes and discriminates between sera from normal and Candida albicans-infected individuals. Clinical Immunology and Immunopathology 33:199-209. 